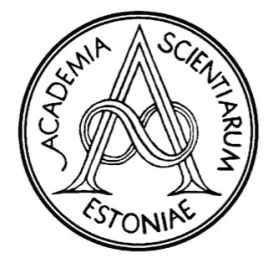

Proceedings of the Estonian Academy of Sciences, $2021,70,2,172-189$

https://doi.org/10.3176/proc.2021.2.07

Available online at www.eap.ee/proceedings

\title{
RC bridge management optimisation considering condition assessment uncertainties
}

\author{
Sander Sein ${ }^{\mathrm{a} *}$, Jose Campos Matos ${ }^{\mathrm{b}}$, Juhan Idnurm ${ }^{\mathrm{a}}$, Martti Kiisa ${ }^{\mathrm{c}}$ and Mário Coelho ${ }^{\mathrm{b}}$ \\ ${ }^{a}$ Department of Civil Engineering and Architecture, Tallinn University of Technology, Ehitajate tee 5, 19086 Tallinn, Estonia \\ ${ }^{\mathrm{b}}$ Institute for Sustainability and Innovation in Structural Engineering, Minho University, Campus de Azurém, 4800-058 Guimarães, \\ Portugal \\ ${ }^{\mathrm{c}}$ Institute of Civil Engineering, Tallinn University of Applied Sciences, Pärnu mnt. 62, 10135 Tallinn, Estonia
}

Received 5 February 2021, accepted 9 April 2021, available online 29 April 2021

(C) 2021 Authors. This is an Open Access article distributed under the terms and conditions of the Creative Commons AttributionNonCommercial 4.0 International License (http://creativecommons.org/licenses/by-nc/4.0/).

\begin{abstract}
Decision-making in bridge management has changed considerably in the past two decades and owners are additionally considering what types of interventions to implement, but correct decisions still need certain input. In Estonia, like in many countries, bridge management is based on inventory records and condition information. The main emphasis of this investigation is on improving the regular condition assessment. More accurate non-destructive testing methods and optimised inspection scheduling are proposed, to reduce condition assessment uncertainties. A conversion matrix for translating additional assessment results to the rating scale of the current Estonian Transport Administration management system is introduced and uncertainties in the condition state are analysed probabilistically. In addition, stochastic degradation models based on existing information are investigated to help considering uncertainties as a part of the overall management process. What impact the adopting of quantitative assessment, rather than qualitative visual inspection, may have on the suggested interventions schedule is also analysed. The probabilistic characteristics of the condition profiles of the most common bridge elements are computed using Markov Chain Monte Carlo stochastic simulation. The optimisation of inspection scheduling is performed considering the uncertainty of the initial deterioration model. When a threshold value, defined by the owner, is reached, the model is updated with assessment data to maintain the level of uncertainty below that threshold. The results confirm that deviations in the degradation model and assessment results influence the bridge condition uncertainty. Likewise, times of both inspection and intervention are influenced, which will ultimately impact the overall management reliability and costs.
\end{abstract}

Key words: bridge management, condition assessment, non-destructive testing, visual inspections, optimisation.

\section{INTRODUCTION}

Bridges are one of the most critical components of the transport network and they require regular investments to maximise economic and societal benefits. Efficient bridge management should meet the present and future needs of the users, normally under the pressure of limited funding. In the past three decades, these investments have been planned, managed, and technically supported by bridge management systems (BMS). BMS basic components are the following: inventory database, deterioration models, optimisation models and update functions (AASHTO 1993). Hence, the management process starts with a correctly formulated database, where relevant condition information is also stored.

\footnotetext{
${ }^{*}$ Corresponding author, sander.sein@taltech.ee
} 
In most countries, the condition information is obtained from visual inspections (Kušar and Šelih 2014; Mirzaei et al. 2014), a method that is the most basic level in the hierarchy of structural assessment of existing structures (Rücker et al. 2006) and is based on qualitative expert judgement. It is a vague measure for the deviation of the inspected bridge from the "as new" condition as described by Hajdin et al. (2018). While this quick and cost-effective procedure, particularly when large bridge stocks are being managed, remains the main assessment method in the next years (Kušar et al. 2019), it has been criticised for being an unreliable method for the evaluation of the condition state of bridges (Phares et al. 2004).

The main source of uncertainty in visual inspections is related to its subjectivity, which means that different inspectors, under similar conditions, may evaluate differently the condition state of the bridge (Corotis et al. 2005; Kušar 2014; Sein et al. 2019). On the other hand, visual inspection outcome does not consider safety and serviceability aspects (Hajdin et al. 2018). The additional problem with the subjective visual inspection method is related to triggering maintenance actions without revealing information about the bridge's inner structure. Thus, the results of inspections alone do not allow medium- or long-term planning and additional strategies must be developed (Neves, Frangopol and Cruz 2006; Neves, Frangopol and Petcherdchoo 2006; Taffe 2018). With qualified inspectors and proper guidelines, valuable information can be provided regarding construction methods, weathering, mechanical damage, deterioration, deficiencies, or other faults. To minimise the error arising from subjectivity, it is important to define standard assessment procedures (Rücker et al. 2006), as already done in a number of countries (Mirzaei et al. 2014). Moreover, throughout the past years, there have been numerous international projects concentrating on the development of advanced approaches for bridges both at the European level, such as quantifying the value of structural health monitoring (COST Action TU1402. 2015) or standardising the overall quality control of existing roadway structures (COST Action TU1406. 2015), and at the national level, projects like forming a bridge management system called the LeCIE_tool in Austria (Zambon et al. 2018).

To quantify the uncertainty of inspection, it is suggested that probabilistic values be used like the probability of detection, probability of false alarm (Rouhan and Schoefs 2003), probability of false indications (Straub and Faber 2003) or even the probability of good or wrong assessment (Sheils et al. 2012), with the main target to minimise the service life costs. Other approaches have tried to cover the inspection uncertainty related issues with overall asset management problems like rehabilitation timing (Zhang et al. 2008) or optimisation of lifecycle costs of bridge utilisation (Ghodoosi et al. 2018). All previous approaches can provide additional value to decision-making, but the methods are not causally linked to owners' needs, e. g. the time between inspections or differences between assessment methods.

Taffe (2018) listed different methods for condition assessment and proposed a procedure of how data would meet the demands of the owner as customer. Although the work concentrated on the information of the inner structure, the issues regarding the definition of the measurand, identification of the method, location and timing of condition assessment are relevant. The proposed procedure targets accuracy of the results to guarantee their reliability, which means that precision should be ensured with the uncertainty of the measurement, which should be statistically evaluated using Guide to the Expression of Uncertainty in Measurement (GUM) (JCGM 2008) and the trueness must be provided by well-trained personnel (Taffe 2018). The main idea behind the quantification of knowledge is to identify the quantities influencing the results (Fig. 1) and allow to draw reliable conclusions (Taffe and Gehlen 2009), which should meet the minimum requirements of the client, not minimal in absolute (Taffe 2018). The framework was used in static calculations, but a similar approach and calculation methods can be utilised in the condition assessment of existing bridges because the outcome is also statistically evaluated.

The credibility of the measurand varies in correlation with the uncertainty of measurement, since the condition index is a value without an exact result and the result of the measurement is unknown. The uncertainty of measurement in the context of the condition index shows that the obtained value is better estimated with presently available knowledge (Hofer 2018). For the decision-maker, the effect of subjective visual inspection on the condition profile is especially important and may show high impact. Ilbeigi and Pawar (2020) developed a two-dimensional Markov process model that involved the current condition and the number of years an element has been in this condition. In combination with risk tolerance, they detected 


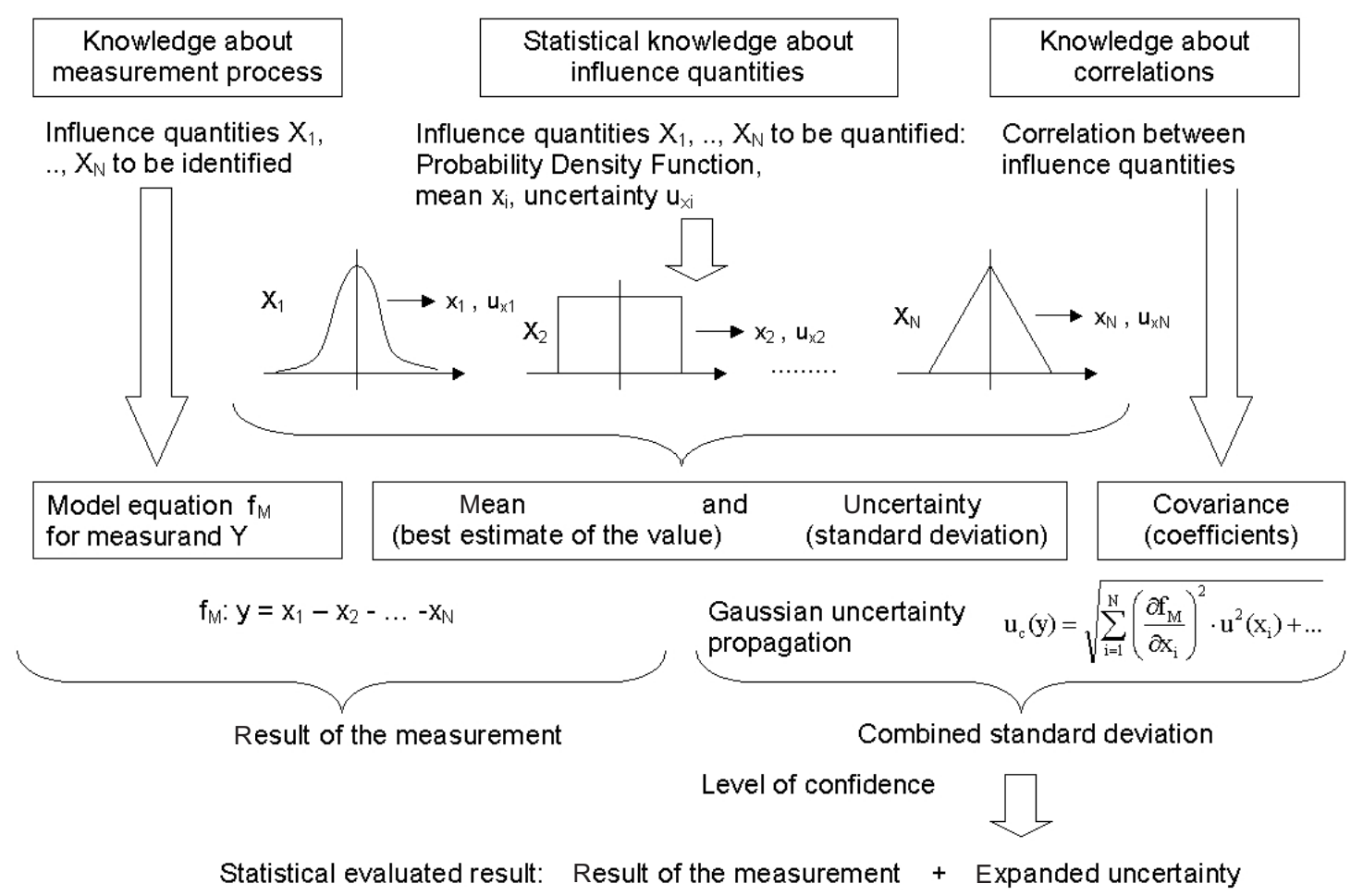

Fig. 1. Flowchart of knowledge about the measurement process and quantities influencing the outcome presented by Taffe and Gehlen (2009), based on GUM (JCGM 2008).

the optimal interval of visual inspections. The results indicated that the typical inspection interval was pessimistic and the optimal inspection interval for bridges in good condition could be 10 to 20 years, which is a notable difference from the common 4- or 5-year interval.

To improve the quality and reliability of collected information, appropriate quantitative and repeatable non-destructive testing (NDT) has been suggested (Kušar et al. 2019). Identification and selection of appropriate methods depend highly on the needs of the operator or owner, but overall, the accuracy of results needs to be assured, which, in turn, can only be estimated when they are correct and reasonably precise (Hässelbarth et al. 2006). Visual inspections are imprecise, and it is difficult to investigate the trueness of assessment even if the design information is available. Contrary to visual inspections, NDT has quantitative results, which makes it more precise, and if as-built information and environmental data are available, it is easier to assess the trueness of the results. In addition to trueness, there are environmental factors, age of different elements and deterioration rates of materials that introduce additional uncertainties that can be investigated using analytical models.

In the current research, the main measurand is the condition state of a specific bridge element group, but overall, the measurand can be any stochastic value representing the condition of a bridge or element. Since the true value of the condition is not known and the assessment of the accuracy of the best estimate is based on expert judgement, different assessment methods are compared within the context of the uncertainties, as well as time interval between inspections and interventions. The best estimate of the condition state is described by using a mean value, while the parameter of uncertainty is the standard deviation of the assessment method. Also, to combine NDT results with visual inspection data, a conversion matrix is proposed with clear threshold values helping the owner to translate the output to the condition. The degradation process is modelled using Markov processes combined with Bayesian updating considering the current condition with a probability distribution and the assessment result with standard deviation based on benchmark testing. Optimisation is performed by using one-dimensional interpolation of time with limit values for condition and uncertainty. 
Although the examples are based on Estonian data, the outcome of this study intends to introduce uncertainty as a part of performance assessment, which helps to determine the inspection intervals and decide which type of assessment should be carried out.

\section{PERFORMANCE ASSESSMENT IN ESTONIA}

The investigated measurand, the condition state, is one of the performance indicators for the national bridge network of the Estonian Transport Administration (ETA), which helps to make decisions regarding intervention actions and restrictions to heavy vehicles. The input data has been collected from the ETA database, including registration and condition information for around 1000 bridges. Regarding condition assessment, the national regulatory documents state that the inspection interval should be three years (Minister of Economic Affairs and Infrastructure 2018) but since 2005 the interval of ETA bridge inspections has been four years. The overall bridge management process is not standardised and does not have clear manuals. It is mainly based on the PONTIS computer program with the numerical rating system (from 1 to 4 ) that uses the element inspection data (Roberts and Shepard 2000).

The performance assessment is mainly based on visual inspections performed with a 4-year interval. During the inspection, all element units of a bridge are assessed on a 4-level condition state, which means that one element can have many condition states. For example, a 10-metre-long beam can have 5 metres in the condition state " 1 " and 5 metres in the condition state " 2 ". The states are also related to intervention activities where the condition state "1" means that the element is as good as new and needs only maintenance, whereas " 4 " means that the elements are deteriorated and need to be replaced. All the elements are taken from a pre-specified list containing more than 100 inputs, which are like commonly recognised bridge elements introduced by AASHTO (Thompson and Shepard 2000).

At the bridge level, as well as at the network level, the main performance parameter is the Condition Index (CI), which is a number between 0 and 100, computed similarly to the Health Index (HI) used in most of the Departments of Transportations in the USA. The HI is defined as a normalised weighted average of the conditions of various elements, providing an overall indication of the health of the structure (AASHTO 2011), but for the CI the overall bridge index is calculated using element weight factors instead of the failure cost of the element. The index should still show the signs of deterioration unless adequate funding is obtained.

Although PONTIS included Markov chain-based degradation models and investment planning (Roberts and Shepard 2000), these modules have never been implemented in Estonian practice due to lack of relevant data preparation. Despite the first steps in the statistical analysis of the collected element information (Sein et al. 2017), using a multivariate methodology, the deterioration is still predicted with linear function or the annual average decay rate. However, before a substantive decision some non-destructive testing is also employed. This approach has been tolerated because in statistical representation the average bridge in Estonia is a small, simply supported beam structure built in 1974, made from reinforced concrete, has a median length of 14.2 metres, and annual investments related to bridge intervention activities have been around 5 to 8 million euros. Nevertheless, the introduced analysis shows clearly that there is room for improvement in performance assessment.

\section{INVESTIGATION METHODOLOGY}

The current research consists of three separate analyses, where the first two are related to real data. The first one is carried out to verify that the data-based degradation models of the historical condition are fit for purpose. In the second analysis, the differences in the interpretation of assessment results used for updating the model are presented and compared. Finally, the third analysis tests the application of optimal inspection scheduling based on the condition and uncertainty threshold.

The division is necessary because the condition information is estimated on real data, where data regarding all maintenance actions is missing and the results should be verified before using them in optimal inspection 


\begin{tabular}{|c|}
\hline \multicolumn{2}{|c|}{ Degradation model and verification } \\
\hline Historical data \\
\hline \multicolumn{2}{|c|}{ Model updating and com parison } \\
\hline Assessment type (time, result, uncertainty) \\
\hline \multicolumn{2}{|c|}{ Bayesian updating } \\
\hline Inspection scheduling \\
\hline Limit values (uncertainty, condition) \\
\hline \\
Con parison of current and optin ised situations \\
\hline
\end{tabular}

Fig. 2. Flowchart of the main elements of the proposed framework.

scheduling. In both of the first two analyses, the details from previously published studies were combined. The flowchart in Fig. 2 shows the different parts of the proposed framework.

The flowchart contains the main parts which can generally be divided into four, but the following steps are taken in more detail:

(1) Preparation of historical information to filter out typical bridges without registered interventions;

(2) Calculation of transition probability matrices for main element groups using the Markov model and Monte Carlo simulation;

(3) Verification of degradation models;

(4) Collection of additional information by means of inspections and non-destructive testing;

(5) Calculation of the condition with updated information;

(6) Comparison of model output based on the assessment method;

(7) Setting limits to the condition state;

(8) Determination of the maximal time frame to the next intervention action by combining the deterioration model and uncertainties in the model;

(9) Setting a limit to uncertainty in performance assessment;

(10) Determination of optimal inspection intervals to keep the uncertainty and condition state under the desired level.

\section{DEGRADATION MODEL}

The condition degradation model is a probabilistic model based on transition probabilities. In general, the values can be obtained either from accumulated condition data or by using an expert judgement elicitation procedure, which requires the participation of several experienced bridge engineers (Thompson and Shepard 2000). In this paper, the transition probabilities are obtained from accumulated condition data employing continuous-time Markov processes. The degradation models were calculated using a part of the software developed by Denysiuk et al. (2017), which were based on the details of Ferreira et al. (2014). These processes are used for two reasons (Kallen and van Noortwijk 2006):

(1) these models are suitable to implement when intervals between inspections are not regular;

(2) it is possible to include the uncertainty associated with irregular times between inspections in the model results.

\section{FORMULATION OF THE MARKOV MODEL}

A continuous Markov chain defines the condition state of an element in terms of a discrete variable and the transition between condition states is defined by an intensity matrix $Q$ (Eq.1) (Jackson 2011): 


$$
Q=\left[\begin{array}{cccc}
-\theta_{1} & \theta_{1} & 0 & 0 \\
\vdots & \vdots & \ddots & \vdots \\
0 & 0 & -\theta_{i} & \theta_{i} \\
0 & 0 & 0 & 0
\end{array}\right] .
$$

The intensity matrix $Q$ defines the average instantaneous transition probability $\theta_{i}$ of moving from one condition state to another and allows that the transitions between the different states can occur on a continuous timescale. The initial estimation of transition probability from historical data is calculated as below (Eq. 2) (Jackson 2011):

$$
\theta_{i}=q_{i j}=\frac{n_{i j}}{\sum \Delta t_{i}}
$$

where $n_{i j}$ is the number of elements that moved from state $i$ to state $j$ and $\sum \Delta t_{i}$ is the sum of intervals between observations. In a continuous Markov chain, the transition probability $P$ and the time $\Delta t$ to move from one condition state to the next is characterised by the exponential distribution of the Chapman-Kolmogorov equation (Eq. 3) (Kallen and van Noortwijk 2006):

$$
P=e^{Q \times \Delta t}=\sum_{n=0}^{\infty} \frac{(Q \times \Delta t)^{n}}{n !} .
$$

To allow the consideration of uncertainties in the condition evaluation process, the final condition state profiles are computed using Monte Carlo simulation (Neves and Frangopol 2005) and the quality of fit is improved through an optimisation process by maximising the log-likelihood function (Eq. 4) (Denysiuk et al. 2017):

$$
\sum_{m=1}^{M} \sum_{n=1}^{N} \log \left(p_{i j}\right)
$$

where $m$ is equal to the number of transitions observed in the element group, $n$ is equal to the number of analysed elements and $p_{i j}$ is the transition probability of the observed transitions predicted by the Markov model.

\subsection{Verification of the degradation models}

In the current investigation, the initial condition database consists of information for one of the most common bridge types, which is a simply supported reinforced concrete beam bridge with mostly precast elements. The elements are categorised differently from the condition state element classification into 16 groups including structural and non-structural elements (Table 1), using the classification of Sein et al. (2017). Since these groups had not been used in the system, the results of Markov models were verified with a goodnessof-fit test under the assumption that the goodness-of-fit follows a $\chi_{n}^{2}$ distribution. In a typical deterioration model, only natural transitions from one condition to another are considered, and transitions that might occur because of maintenance actions are excluded. However, in Estonia the maintenance actions have not been recorded correctly and thus may affect the overall decay rate. The goodness-of-fit is measured by the discrepancy between the observed number of transitions and the expected number of transitions (Eq. 5):

$$
T=\sum_{i=1}^{C} \frac{\left(O_{i}-E_{i}\right)^{2}}{E_{i}},
$$

where $T$ is the goodness-of-fit metric, $C$ denotes the number of possible condition state transitions (10 transitions), $O_{i}$ refers to the observed number of transitions and $E_{i}$ is the expected number of transitions of each time. The null hypothesis was assumed similarly to Ferreira et al. (2014), where Markov models were considered correct if the probability of goodness-of-fit is better than $5 \%$ of the sample value (Eq. 6):

$$
P\left(T>T_{o b s}\right) \geq 5 \% .
$$

The overall results are presented in Table 1 . The limit value of $\chi_{n}^{2}$ distribution for $5 \%$ significance level was calculated as below (Eq. 7):

$$
T>\chi_{(11-1)-4: 0.05}^{2}=16.919 .
$$


Table 1. Goodness-of-fit test of deterioration models

\begin{tabular}{|c|c|c|c|c|c|}
\hline $\begin{array}{c}\text { Non-Structural } \\
\text { elements }\end{array}$ & Observations & $\begin{array}{c}\text { Discrepancy } \\
\text { (T) }\end{array}$ & $\begin{array}{l}\text { Structural } \\
\text { elements }\end{array}$ & Observations & Discrepancy (T) \\
\hline Overlay & 222 & 1.87 & Deck plate & 253 & 1.34 \\
\hline Barriers & 198 & 4.37 & Edge beam & 189 & 1.21 \\
\hline Handrails & 169 & 0.69 & $\begin{array}{l}\text { Piles and } \\
\text { columns }\end{array}$ & 64 & 0.78 \\
\hline Drainage & 43 & 0.13 & Supporting beam & 212 & 4.73 \\
\hline Slopes & 231 & 2.31 & $\begin{array}{l}\text { Wing wall, } \\
\text { abutments }\end{array}$ & 203 & 2.42 \\
\hline Deformation joints & 177 & 0.67 & Diaphragms & 155 & 0.85 \\
\hline $\begin{array}{l}\text { Other (riverbed, } \\
\text { signs, etc.) }\end{array}$ & 155 & 29.79 & Main girder & 215 & 1.06 \\
\hline Waterproofing & 253 & 16.75 & Bearings & 121 & 0.89 \\
\hline
\end{tabular}

Based on the results presented in Table 1, only the non-structural element group designated "Other" did not pass the test, which means that there is adequacy between the sample and the model of all other element groups.

\section{MODEL UPDATING}

To include information from additional assessment, the initial deterioration model should be successively updated. The updating approach is based on the use of Bayesian updating combined with simulation and expert judgement proposed by Neves and Frangopol (2005). There are two differences in the current model compared to the initial work:

(1) the performance of structures was defined in terms of lifetime probabilistic condition, safety, and cost profiles. The condition index was combined with more consistent indicators such as the safety index, but in the current work only the condition index profile is used.

(2) the initial model did not include any information resulting from inspections or non-destructive tests, as it was based on the performance evolution over time obtained by using expert judgement alone. However, in the current analysis, additional information is included.

Similarly to the initial work, the mean, standard deviation, histograms, and percentiles of the life-cycle condition index are computed employing Monte Carlo simulation.

\subsection{Formulation of the inference process}

At the time of an inspection, the condition index can be characterised as a probabilistic variable, with a probability density function dependent on the results obtained by the inspector, but also on the quality of the inspection. Common practice defines the results of an inspection in terms of a set of possible outcomes $(0,1 \ldots, n)$. However, deterioration is considered a continuous or almost continuous evolution, and the results presented based on the simulation are a simplification of reality towards a pessimistic approach. In other words, this means that the real condition is always assumed to be worse than the average value. Based on the Bayes theorem, the probability density function of the condition including the results of the inspection can be defined as below (Eq. 8) (Neves and Frangopol 2008):

$$
f^{\prime \prime}\left(C_{T}\right)=L\left(C_{T}\right) \times f^{\prime}\left(C_{T}\right),
$$

where $f^{\prime \prime}\left(C_{T}\right)$ is the probability density function of the condition at the time $T$ by considering both inputs that are present in posterior distribution, $f^{\prime}\left(C_{T}\right)$ represents the probability density function of the condition at the time $T$ by considering only assessment, $L\left(C_{T}\right)$ is the likelihood function. 
For the Monte Carlo simulation, the mean and standard deviation of assessments at the time $\tau$ were calculated as below (Eq. 9) and (Eq. 10) (Neves and Frangopol 2008):

$$
\begin{aligned}
& \mu_{C}^{\tau}=\frac{\sum_{i=1}^{n} c_{\tau}^{i} \times L\left(c_{T}^{i}\right)}{\sum_{i=1}^{n} L\left(c_{T}^{i}\right)}, \\
& \sigma_{C}^{\tau}=\sqrt{\frac{\sum_{i=1}^{n} C_{\tau}^{i} \times L\left(c_{T}^{i}\right)}{\sum_{i=1}^{n} L\left(c_{T}^{i}\right)}-\left(\frac{\sum_{i=1}^{n} c_{\tau}^{i} \times L\left(C_{T}^{i}\right)}{\sum_{i=1}^{n} L\left(c_{T}^{i}\right)}\right)^{2}},
\end{aligned}
$$

where $\mu_{C}^{\tau}$ and $\sigma_{C}^{\tau}$ are the mean and standard deviations of the condition at the time $\tau$ including the model and assessment, $C_{\tau}^{i}$ is the condition at the time $\tau$ connected to the sample $i, C_{\tau}^{i}$ is the condition at the time $T$ connected to sample $i$ and $n$ is the number of samples.

\subsection{Conversion matrix}

Visual inspections of existing structures are a prime source of information in every assessment and a part of a management system. The observations can give reliable information on the structures and are normally integrated with prediction models for the assessment of deterioration in the infrastructure network. Nevertheless, using only visual inspections in decision-making makes the overall process less rational and more based on engineering judgement. While moving from prescription-based to performance-based quality control, the tendency to carry out additional non-destructive testing has increased. It can provide a more complete evaluation and might suggest maintaining the load-bearing components of the structure instead of more costly repair or reconstruction.

One reason why additional testing was not implemented in initial decision-making is related to the missing connection between different assessment results. For example, in Estonia the condition state description has an additional intervention suggestion, but NDT standards or manuals have only procedure descriptions and thus additional expert knowledge is needed. To enhance the use of NDT, the authors have compiled a table of suggested threshold values for some basic methods (Table 2).

The values in Table 2 are suggested by the authors based on the previous tests or research carried out in Estonia, the table is not complete and may be expanded with additional suitable NDT. The identification of criteria for potential NDT has been investigated by Kušar et al. (2019), where the suitable method was chosen based on the results' reliability, test duration, results' interpretation complexity, cost, usability, and standardisation.

\begin{tabular}{|c|c|c|c|}
\hline $\begin{array}{l}\text { Condition state, } \\
\text { intervention } \\
\text { recommendation }\end{array}$ & Carbonation depth [mm] & Chloride content [\%] & $\begin{array}{c}\text { Resistance of concrete } \\
\text { (Andrade and Alonso } \\
\text { 2004) }[\mathrm{kOhmcm}]\end{array}$ \\
\hline $\begin{array}{l}1 \text { - very good, regular } \\
\text { maintenance }\end{array}$ & $\begin{array}{l}\text { Average carbonation depth is } \\
\text { less than } 25 \% \text { of measured } \\
\text { cover depth }\end{array}$ & $\begin{array}{l}\text { Average measured value is } \\
\text { less than } 100 \% \text { of the } \\
\text { normative threshold value }\end{array}$ & Above 100 \\
\hline 2 - good, local repairs & $\begin{array}{l}\text { Average carbonation depth is } \\
\text { between } 25 \% \text { and } 50 \% \text { of } \\
\text { measured cover depth }\end{array}$ & $\begin{array}{l}\text { Average measured value is } \\
\text { between } 101 \% \text { to } 150 \% \text { of } \\
\text { the normative threshold } \\
\text { value }\end{array}$ & Between 50 and 100 \\
\hline $\begin{array}{l}3 \text { - poor, overall } \\
\text { repair }\end{array}$ & $\begin{array}{l}\text { Average carbonation depth is } \\
\text { between } 50 \% \text { and } 100 \% \text { of } \\
\text { measured cover depth }\end{array}$ & $\begin{array}{l}\text { Average measured value is } \\
\text { between } 151 \% \text { to } 200 \% \text { of } \\
\text { the normative threshold } \\
\text { value }\end{array}$ & Between 10 and 49 \\
\hline $\begin{array}{l}4 \text { - extremely poor, } \\
\text { replacement or } \\
\text { reconstruction }\end{array}$ & $\begin{array}{l}\text { Average carbonation depth is } \\
\text { more than measured cover } \\
\text { depth }\end{array}$ & $\begin{array}{l}\text { Average measured value is } \\
\text { more than } 200 \% \text { of the } \\
\text { normative threshold value }\end{array}$ & Less than 10 \\
\hline
\end{tabular}

Table 2. Conversion matrix of the NDT result to the condition state 
Table 3. Assessment results of typical bridges

\begin{tabular}{|c|c|c|c|c|c|c|c|}
\hline \multirow{2}{*}{$\begin{array}{l}\text { Bridge } \\
\text { No. }\end{array}$} & \multirow{2}{*}{$\begin{array}{c}\text { Construction } \\
\text { year }\end{array}$} & \multirow{2}{*}{$\begin{array}{c}\text { Reconstruction } \\
\text { year }\end{array}$} & \multicolumn{2}{|c|}{ Inspection-based } & \multicolumn{2}{|c|}{ Carbonation depth } & \multirow{2}{*}{$\begin{array}{c}\mathrm{CS} \\
\text { differences }\end{array}$} \\
\hline & & & $\begin{array}{c}\text { Time of } \\
\text { inspection }\end{array}$ & $\begin{array}{c}\mathrm{CS}- \\
\text { intervention }\end{array}$ & $\begin{array}{c}\text { Average } \\
\text { measurement, } \\
\mathrm{mm} \\
\end{array}$ & $\begin{array}{c}\mathrm{CS}- \\
\text { intervention }\end{array}$ & \\
\hline 883 & 1989 & 2002 & 2015 & $1.1-\mathrm{M}$ & 6.9 & $1.4-\mathrm{M}$ & +0.3 \\
\hline 826 & 1969 & 2010 & 2019 & $1.1-\mathrm{M}$ & 18.7 & $2.3-\operatorname{Rep}$ & +1.2 \\
\hline 907 & 1967 & 2001 & 2019 & $1.2-\mathrm{M}$ & 20.0 & $2.8-\operatorname{Rep}$ & +1.6 \\
\hline 911 & 1970 & 1998 & 2019 & $1.3-\mathrm{M}$ & 28.0 & $2.8-\operatorname{Rep}$ & +1.5 \\
\hline 908 & 1967 & 2001 & 2019 & $1.7-\mathrm{M}$ & 13.6 & $2.6-\operatorname{Rep}$ & +0.9 \\
\hline 503 & 1969 & - & 2019 & $2.1-\operatorname{Rep}$ & 26.2 & $3.5-$ Ren & +1.4 \\
\hline 252 & 1965 & 2000 & 2018 & $2.3-$ Rep & 3.2 & $1.2-\mathrm{M}$ & -1.1 \\
\hline 909 & 1974 & - & 2019 & $2.3-$ Rep & 37.5 & $3.5-$ Ren & +1.2 \\
\hline 306 & 1969 & - & 2019 & $3.0-$ Ren & 10.8 & $2.2-$ Rep & -0.8 \\
\hline
\end{tabular}

\subsection{Assessment outcome comparison}

To present the use of the conversion matrix and draw attention to the difference of the potential outcome as intervention activity for one specific element group, several bridges have been tested in the past years. The data presented in Table 3 were collected from the precast beams of nine bridges with the following common properties: made of reinforced concrete, simply supported beam bridges without additional diaphragms, constructed between 1965-1989 and designed according to the standard design of the Soviet Union, Catalogue No. 56-addition (USSR Mintransstroy 1962) or Catalogue No. 167 (USSR Mintransstroy 1963). The condition states of inspections (CS) are calculated based on the assessment result of element units and for carbonation depth, the result is interpolated. Possible intervention activities are regular maintenance (M), repair (Rep) or renovation/renewal (Ren).

It is possible to notice that only one bridge has the same potential intervention outcome, but in most cases, different assessment types have different outcomes. With two exceptions the inspection-based condition state is lower than the carbonation depth-based condition state, which means that the element should be repaired but is maintained instead (4 out of 9) or the element should have already been replaced or renovated but is repaired (2 out of 9$)$.

The obtained results justify the question about the knowledge of uncertainties in the interpretation of data, because using only one assessment result as a trigger for intervention may lead to inefficient management. To consider the different assessment results, a confidence level of $95 \%$ is used in finding the optimal inspection interval and the inspection result is assumed to be the same as the average degradation model value. To improve the quality of data interpretation, it is suggested that the stochastic model should be combined with analytical models. For example, Zambon et al. (2019) has presented a framework where the analytical model of carbonation was combined with a Markov chain model.

\section{UNCERTAINTIES IN PERFORMANCE ASSESSMENT}

Apart from the non-trivial combination of different methods, also the uncertainty of assessment plays an important role in more accurate results and in moving towards optimal inspection intervals. When the value of a bridge condition is reported, in addition to the best estimate of its value, the best evaluation of the associated uncertainty should also be given, as it is not normally possible to decide in which direction the realistic condition of the bridge element is from the assessed condition and whether it performs as intended. 
If the uncertainties are understated, then too much trust might be put in the values reported, which may lead to undesired consequences. Likewise, the overstatement of uncertainties could also have undesirable repercussions. For example, it could cause unnecessary interventions, making structure maintenance more costly.

Uncertainty, namely epistemic uncertainty, originates from various sources, and based on the classification of Regan et al. (2002), it can be divided into six classes:

- Inherent randomness, which is the uncertainty related to the randomness of the inherent nature affecting the outcome. This type of uncertainty can be quantified using probabilistic models;

- Measurement error, which is the uncertainty related to measured quantity and errors. This type of uncertainty can be quantified using probabilistic models if the measurement error is estimated;

- Systematic error, which is the uncertainty related to the bias of measurements or sampling. This type of error can be quantified but is difficult to notice and use in probabilistic models;

- Natural variation, which is the uncertainty related to natural conditions. Since the changes in natural conditions are unknown, careful consideration is needed before quantification of this type of uncertainty;

- Model uncertainty, which is the uncertainty related to the model abstraction of the real process. This type of uncertainty also needs careful consideration before quantification. Additionally, cause-and-effect relationships are exceedingly difficult to quantify;

- Subjective judgement, which is the uncertainty related to the interpretation of data. This type of uncertainty is difficult to quantify, similarly to model uncertainty.

In bridge management, all the described types of uncertainty are present, and it is impossible to separate them from each other. To help the bridge owners to make justified decisions and be aware of various sources of uncertainty, it is proposed that a limit to expanded uncertainty should be obtained which defines an interval with a specified level of confidence, and which satisfies their needs. However, the Joint Committee for Guides in Metrology (JCGM) suggests in their guidance (Bich et al. 2006) that such factors must be applied to the uncertainty as determined by a realistic method, where the uncertainty has been determined, the interval defined by the expanded uncertainty has the level of confidence required and the operation may be easily reversed. There are three distinct advantages of adopting an interpretation of probability based on the degree of belief, standard deviation, and the law of propagation of uncertainty as the basis for evaluating and expressing the uncertainty in measurement (JCGM 2008):

- The law of propagation of uncertainty allows the combined standard uncertainty of one result to be readily incorporated in the evaluation of the combined standard uncertainty of another result in which the first is used;

- The combined standard uncertainty can serve as the basis for calculating intervals that correspond in a realistic way to their required levels of confidence;

- It is unnecessary to classify components as "random" or "systematic" (or in any other manner) when evaluating uncertainty because all components of uncertainty are treated in the same way.

Although the JCGM (2008) guide states that when the standard uncertainty of an input quantity cannot be evaluated by an analysis of the results of an adequate number of repeated observations (stated as Type A evaluation), a probability distribution must be adopted based on knowledge or expert judgement (stated as Type B evaluation) which is much less extensive than might be desirable. That does not, however, make the distribution invalid or unreal; like all probability distributions, it is an expression of what knowledge exists. Therefore, measurement-based evaluations of standard uncertainty are not necessarily more reliable than knowledge-based evaluations (JCGM 2008). In the current framework, both types of evaluations are possible to use, but to increase the reliability of results, a comparison between uncertainties obtained by different test methods, with multiple benchmarking tests involving experts and novice users, was carried out by Sein et al. (2019). Based on those results, the measurement-based uncertainty is expressed as the coefficient of variation in Eq. 11:

$$
\mathrm{CoV}=\frac{\sigma}{\mu}
$$

where $\sigma$ is the standard deviation, $\mu$ denotes the mean of the measurement and $\mathrm{CoV}$ is the ratio or relative standard deviation. Inspection related uncertainty values are based on benchmarking and presented as a 
Table 4. Overview of uncertainties of different assessment methods (Sein et al. 2019)

\begin{tabular}{l|lc}
\hline \multicolumn{1}{c|}{ Method } & \multicolumn{1}{c|}{ Expertise } & $\begin{array}{c}\text { Standard deviation } \\
(\mathrm{CoV} \times 4)\end{array}$ \\
\hline \multirow{3}{*}{ Visual inspection } & Inexperienced students & 1.49 \\
& Engineers & 0.61 \\
Carbonation depth with phenolphthalein method & Experts & 0.50 \\
& Inexperienced students & 0.47 \\
& Experts & 0.35 \\
Cover depth using electromagnetic cover meter & All & 0.19
\end{tabular}

standard deviation of condition assessment (Table 4). The same values are used in the optimal inspection scheduling.

Inspectors with previous expertise can obtain condition state results with lower standard deviation than less experienced ones, but more accurate NDT methods give better results, even for inexperienced users.

If the assessment is combined, then the combined standard uncertainty is calculated by Eq. 12 and used in the likelihood function instead of the standard deviation of a single assessment:

$$
u_{c}=\sqrt{\left((u)_{1}\right)^{2}+\left((u)_{2}\right)^{2} \ldots\left(+(u)_{n}\right)^{2}},
$$

where $u_{c}$ is the combined uncertainty and $(u)_{1,2 . . . n}$ are the standard deviations of separate assessments. For example, when combining cover depth measurement with carbonation depth measurement carried out by experts, the combined standard uncertainty is 0.40 .

\section{INSPECTION SCHEDULING}

The main goal of the inspection scheduling is to keep the level of uncertainty under the desired threshold value by maximising the time between inspections. Based on the investigation of benchmark tests in Estonia (Sein et al. 2019), the inspections are an important part of the bridge management process and even assessment performed by an inexperienced inspector decreases the level of uncertainty in condition prediction. Unfortunately, the visual inspections have limitations due to their subjectivity and to increase the quality of assessment, it is necessary to combine the evaluation with quantitative measurements.

Finding the optimal solution is based on linear interpolation and the outcome is the time of inspection or intervention. The main goal of the optimisation is to maximise the time between inspections while keeping the level of uncertainty under a specified threshold value. As an additional result, the potential intervention can be triggered if the knowledge of the measurand minimises the costs of overall management processes.

The optimisation is based on the linear interpolation of the condition profile with $95 \%$ confidence. Linear interpolation can be expressed in general (Eq. 13):

$$
y=y_{0}+\frac{\left(x-x_{0}\right)\left(y_{1}-y_{0}\right)}{x_{1}-x_{0}},
$$

where $x_{0,1}, y_{0,1}$ are the coordinates of two known points and $x, y$ are the coordinates of the unknown point. The known points are the time and error of predicted or updated conditions and the unknown point is partially defined with the limit value. Limit values for the condition state and uncertainty in the model are related to owners' policies or needs and need to be defined separately. The limit value for the condition state is one main trigger for potential intervention activity or in-depth assessment and the limit value for uncertainty is one main trigger for inspection but can also be used for triggering in-depth assessment or preventive intervention.

To investigate which of the proposed inspection scheduling gives optimal output, two parameters are compared. For uncertainty, a trapezoidal numerical integration is used to calculate the approximate area of uncertainties during the designed service life of 100 years. To simulate costs for the agency, total costs of element inspection and potential intervention are summarised. 


\section{CASE STUDY}

Case study analysis concentrates on the same precast beams of the most common bridges as introduced in Chapter 6.3. The input is based on real values, but the investigation of different assessment methods is theoretical. Different inspection scheduling and assessment methods are compared during the service life of 100 years using the condition limit for triggering intervention. The emphasis is put on the total number of inspections, intervals, overall costs, area of uncertainty and the years when uncertainty is above a threshold value.

The limit values used for the condition and error are set based on the current maintenance policy of the ETA and expert judgement under the assumption that both variables follow a normal distribution and have a confidence level of $95 \%$. Hence, the following restraints are applied:

- Condition state is limited to 3.0 (poor) because the elements look visually bad and most likely a renewal will be triggered within the next few years. Since the investigation is concentrated on inspection interval scheduling, only the decrease in the condition state is considered the only effect of maintenance action. As stated before, then the regular maintenance is included in the initial condition degradation profile.

- Uncertainty of a condition state is only limited to 1.0 because this gives the confidence that the assessed condition stays within the limits of one value. Additionally, currently used non-destructive testing methods are not fully accurate and limiting the uncertainty to lower values triggers inspections every year.

- The initial condition and uncertainties are included in the initial probability distribution, which is based on the expert judgement. For example, Kang and Adams (2010) used random errors of $\pm 10 \%, \pm 20 \%$ and $\pm 50 \%$ in their sensitivity analysis of bridge $\mathrm{HI}$ related element condition assessment. In this investigation, the initial condition accuracy is $\pm 10 \%$, which means that if the initial condition state is one, then the vector of probability distribution is $P(0)=\left[\begin{array}{llll}0.90 & 0.10 & 0 & 0\end{array}\right]$.

- The standard deviation of the degradation model $\sigma_{\text {model }}=0.50$.

- For regular visual inspection with $\sigma=0.50$, a price of 150 EUR is estimated; for cover and carbonation depth measurements with $\sigma=0.40$, a price of 400 EUR is estimated; for advanced NDT assessment including chloride content and resistivity measurements having $\sigma=0.3$, the price is estimated to be 800 EUR.

- Intervention activity is the renewal of a beam during an overall bridge reconstruction and the cost is estimated to be 10000 EUR.

Since the analysis is based on a specific bridge element group, the verified transition intensity matrix is used (Eq. 14).

$$
Q_{\text {beams }}=\left[\begin{array}{cccc}
-0.0100 & 0.0100 & 0 & 0 \\
0 & -0.0237 & 0.0237 & 0 \\
0 & 0 & -0.0137 & 0.0137 \\
0 & 0 & 0 & 0
\end{array}\right] .
$$

The transition probabilities are low because there are only three different visual inspection inputs since 2005 and many new structures are still evaluated in the condition state 1. Based on the presented values, an average condition degradation profile is calculated. Further analyses are carried out using the probabilistic degradation model with a confidence level of $95 \%$ and the previously stated restrictions (Fig. 3).

Due to the low transition probabilities, the average degradation profile is almost linear, which makes the scheduling of intervention activities unrealistic. Nevertheless, considering the errors of the model with $95 \%$ confidence, the renewal of concrete beams is triggered after 43 years in service. In Fig. 4, the probability mass distribution of the degradation model in year 42 is presented, the initial standard deviation has increased from 0.30 to 0.85 . From an optimistic point of view, it means that there is a possibility that the real condition state is still 1.0, but intervention activity is nonetheless triggered. In comparison, taking into consideration that the inspected condition affects the final condition probability mass function, inspection with the result equal to 1.60 is presented.

It is clear that the model with updated information has a lower level of uncertainty and if the result of the assessment is true, then intervention activity can also be postponed. Currently, the condition assessment is 


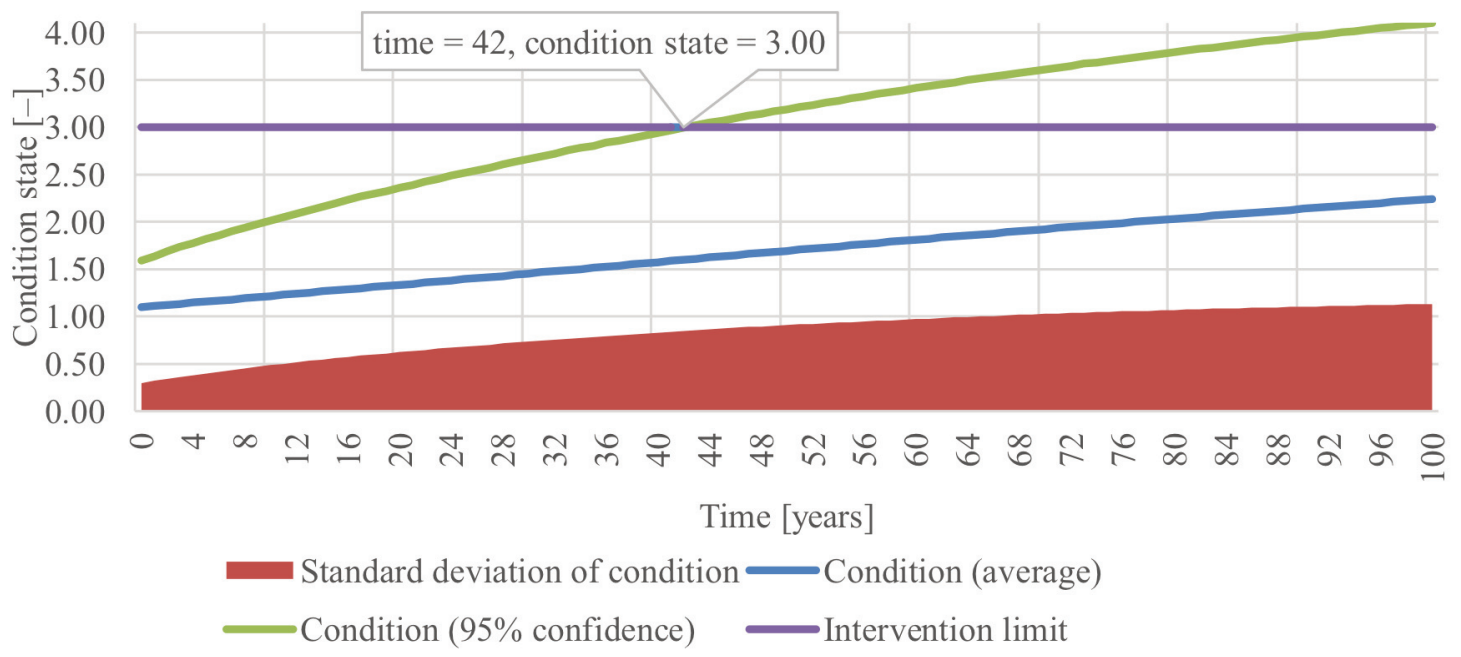

Fig. 3. Condition degradation profile of concrete beams.

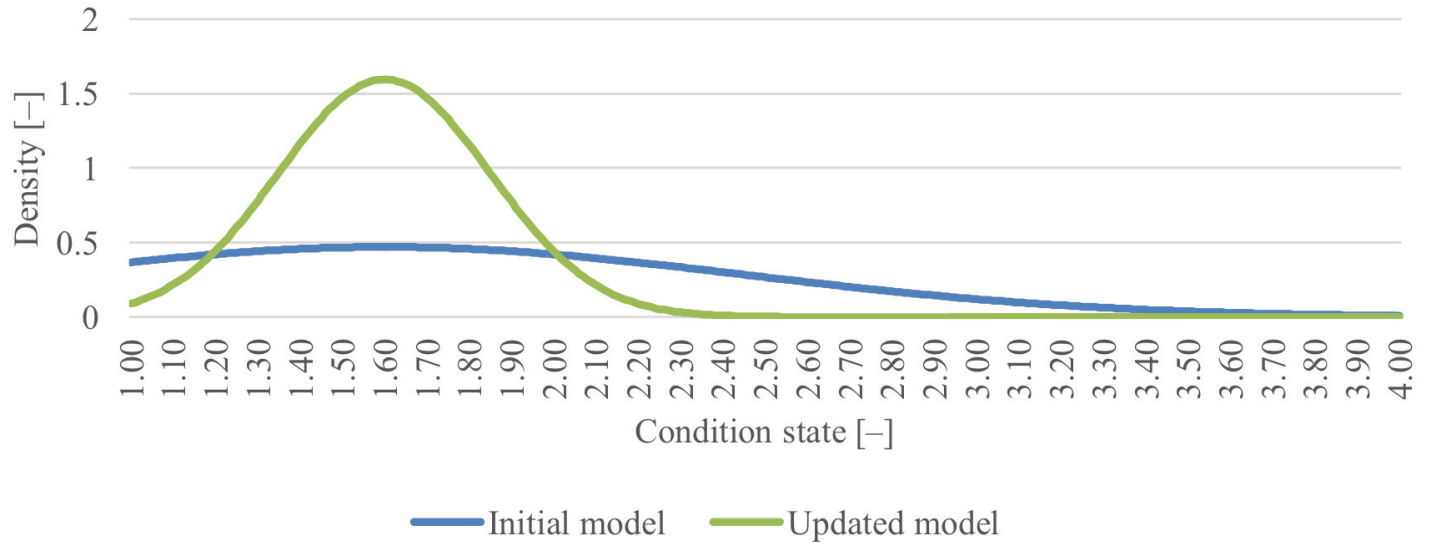

Fig. 4. Probability mass function of the initial and updated models on year 42 .

only visual inspection based, with 4-year intervals. Since the cost of an inspection is low, it is still possible to make the current assessment regulation more optimal with clearer inspection scheduling. The average 4year inspection interval is compared with the optimal inspection interval and the condition profiles are presented in Fig. 5.

Comparing the 4-year interval profile to the initial condition degradation profile in Fig. 3, it is possible to postpone the intervention by 41 years to year 82 with only better knowledge about the condition state. The limit of uncertainty in the optimal inspection interval triggers intervention in year 69 , which is earlier than the current system, but without more accurate inspections the intervention is needed. If the trigger were based on the condition state, then the time of intervention would be in year 76. It is possible to see that before the intervention there are six inspections with an annual interval and this situation could be avoided with a more accurate assessment with the standard deviation $\sigma=0.3$ as presented in Fig. 6 .

Although accurate assessment is more expensive, it reduces the uncertainty and extends the time of the next inspection from 3 years to 6 years. Since the level of uncertainty is still high because of the uncertainties in the model, next inspections should also be performed with additional testing, and eventually it is not possible to postpone the intervention with a more accurate assessment.

Alternatively, it is possible to add cover depth and carbonation measurements to all inspections, with this addition it is possible to decrease the combined standard deviation to 0.40 . The cost of the intervention will 


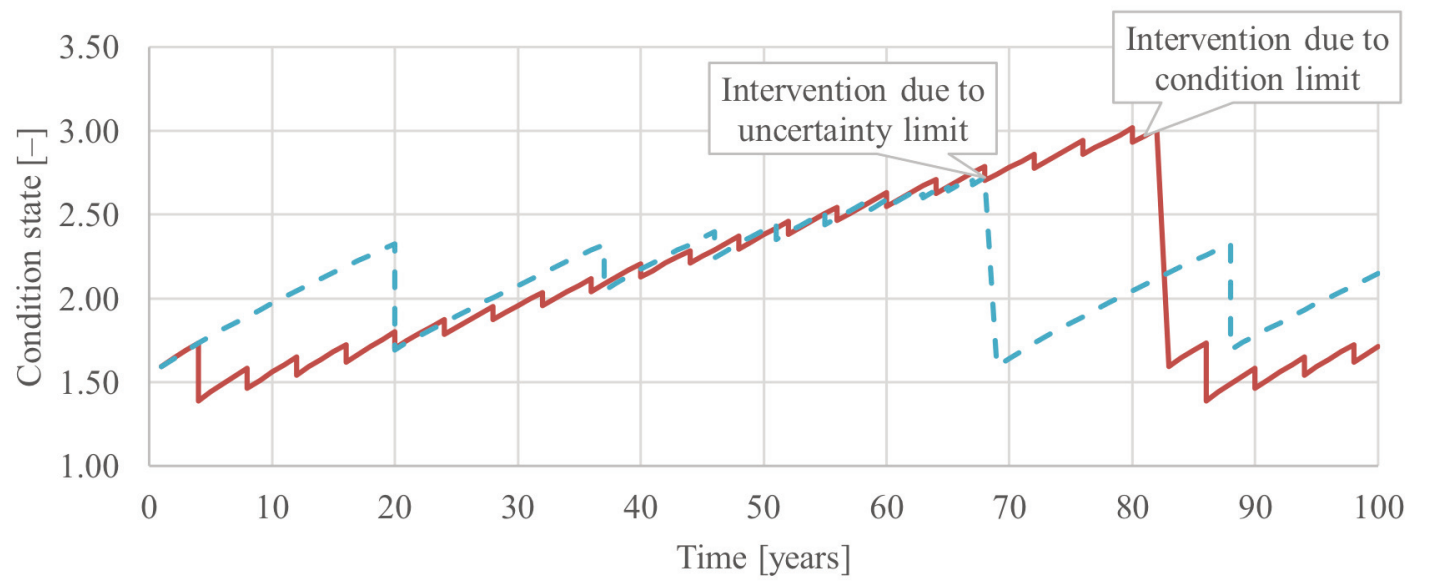

_ Inspections with 4-year interval _ _ - - Optimal inspection interval

Fig. 5. Condition profiles of 4-year and optimal interval visual inspections.

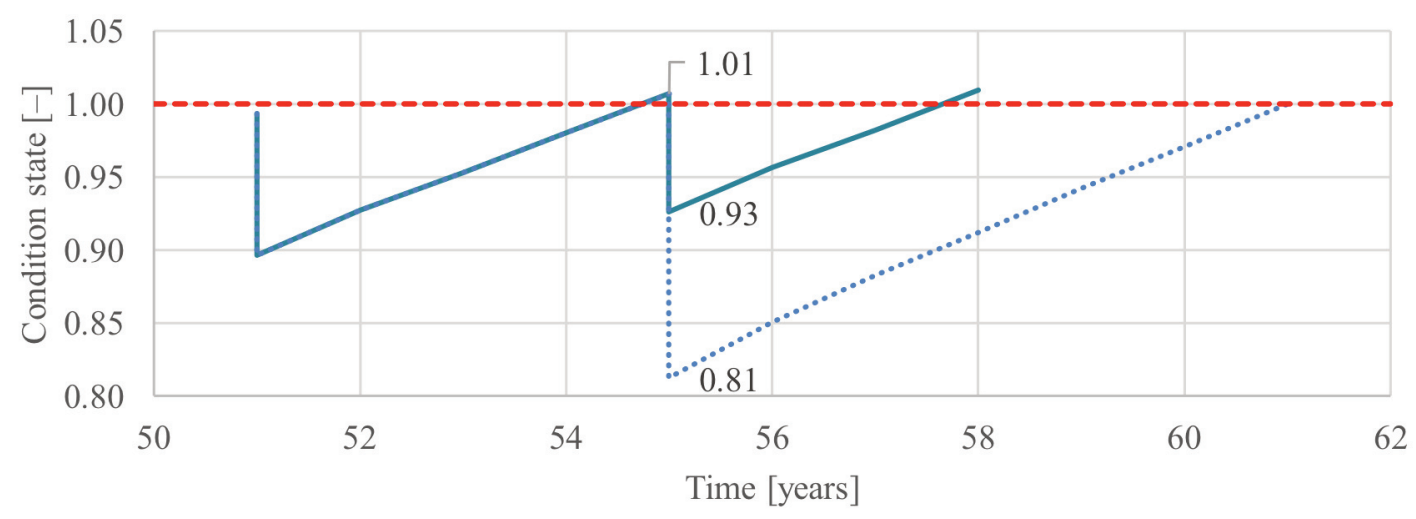

Uncertainty with visual inspections ........ Uncertainty with additional testing
- - Uncertainty limit

Fig. 6. Uncertainties in year 55 with different assessments.

be higher, but in return, the intervention will be triggered later. As in Fig. 5, the average 4-year inspection interval is compared with the optimal inspection interval. The condition profiles are presented in Fig. 7.

In both cases, the intervention is triggered in year 90 due to the condition limit. The main difference between the two approaches is the time between inspections, which is longer with optimal scheduling, as well as the number of inspections. With a 4-year interval, there were 22 inspections, but with the optimised approach, there were only 12 inspections with the intervals ranging from 5 to 19 years. Inspection intervals triggered by the uncertainty limit for visual inspections presented in Fig. 5 varied from 1 year to 20 years, which interestingly corresponds to the results based on optimising the inspection interval for New York bridges (Ilbeigi and Pawar 2020).

In the context of overall management, the overall costs should also be minimised, because more expensive and accurate tests can postpone more costly intervention. However, the situation where the assessment costs are higher than the intervention should be avoided. Assessment methods were compared during the service life of 100 years and an overview of the results is shown in Table 5. 


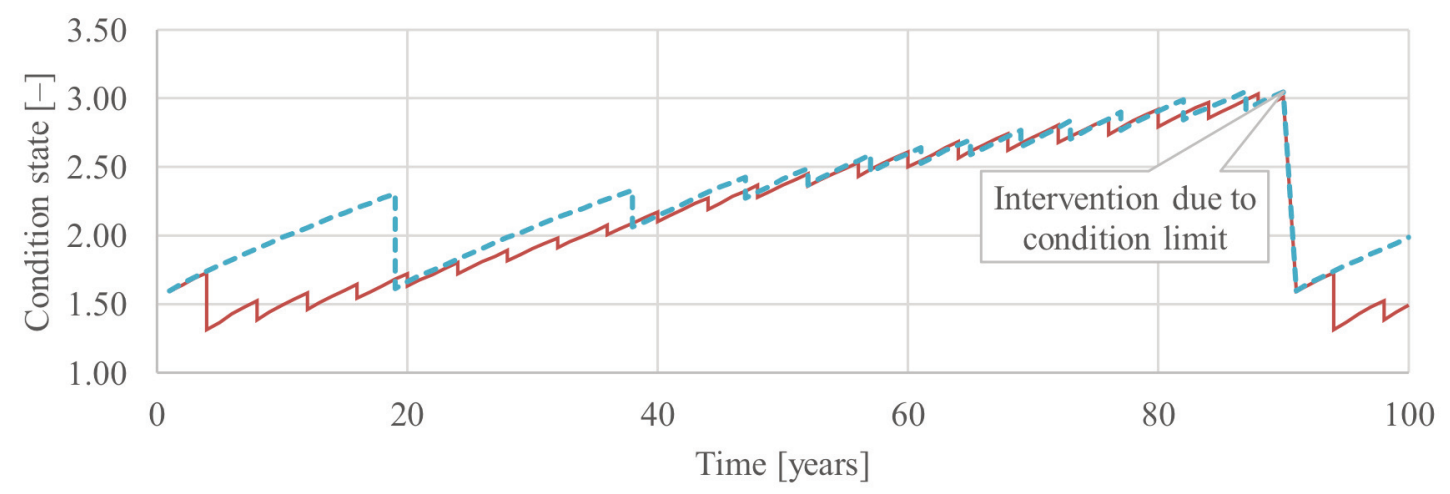

- Inspections with 4-year interval $\quad \ldots-\cdots$ Optimal inspection interval

Fig. 7. Condition profiles of 4-year and optimal interval inspections with additional testing.

Table 5. Overview of total costs and uncertainties with different assessment approaches

\begin{tabular}{l|c|c|c|c|c|c|c}
\hline \multicolumn{1}{c|}{ Assessment type } & $\begin{array}{c}\text { No. } \\
\text { inspections }\end{array}$ & $\begin{array}{c}4 \text {-year } \\
\sigma=0.5\end{array}$ & $\begin{array}{c}\text { Optimal } \\
\sigma=0.5\end{array}$ & $\begin{array}{c}\text { 4-year } \\
\sigma=0.4\end{array}$ & $\begin{array}{c}\text { Optimal } \\
\sigma=0.4\end{array}$ & $\begin{array}{c}\text { 4-year } \\
\sigma=0.3\end{array}$ & $\begin{array}{c}\text { Optimal } \\
\sigma=0.3\end{array}$ \\
\hline Total number of inspections [-] & 0 & 24 & 14 & 24 & 12 & 24 & 7 \\
Total number of interventions [-] & 2 & 1 & 1 & 1 & 1 & 0 & 1 \\
Total cost [EUR] & 20000 & 13600 & 12100 & 19600 & 14800 & 19200 & 15600 \\
Area of uncertainty curve [-] & 141.5 & 75.5 & 82.4 & 73.2 & 84.0 & 68.7 & 80.1 \\
Uncertainty above 1.0 [years] & 81 & 21 & 1 & 0 & 0 & 0 & 0
\end{tabular}

Comparing the triggered interventions, only the most accurate 4-year interval inspections can lead to a situation where no intervention is needed since the intervention is triggered due to the condition in year 103. Contrarily, the approach with no inspections triggered two interventions. The total cost is only $4.17 \%$ higher without any inspections. The lowest total cost results from visual inspections with the optimal interval. Most commonly one intervention is triggered, which means that the cost of intervention affects most of the approaches with the same amount. Although the area of the uncertainty of the optimal approaches is always higher, the uncertainty of the condition is always below the threshold value 1.0, which means that inspections are triggered only when needed and not based on a strict schedule. In the current 4-year interval approach, the inspections are triggered too quickly in the first 55 years and after that the level of uncertainty is higher than the threshold value, meaning that the condition could differ more than one state and intervention or more accurate testing is needed. Improving visual inspections by means of more accurate NDT is also justified because the uncertainty is lower than the threshold value, but the area of uncertainty is higher. Also, after 55 years the time between inspections can only be extended with better knowledge.

\section{CONCLUSIONS}

This paper has focused on intervention-related decision-making and inspection scheduling triggered by uncertainties in regular performance assessment. To integrate more accurate non-destructive testing methods with the currently common visual assessment, a condition conversion matrix and an overview of carried out tests has been presented. The different assessment method of the existing structure will probably lead to different intervention activity. Moreover, the data were theoretically analysed as probabilistic values of the beam condition of the most common bridge type in Estonian national roads. For computation, a Markov Chain Monte Carlo simulation was employed and verified with the Estonian Transport Administration's database. 
Using one-dimensional interpolation of the uncertainty of the deterioration model, it was detected that, although the overall level of uncertainty is lower, the current condition scheduling policy is too pessimistic in the first 55 years after construction and too optimistic afterwards. This finding correlates with suggestions given by Ilbeigi and Pawar (2020) based on the New York bridge network inspection scheduling. The main conclusions about the knowledge of the uncertainty regarding the assessment are as follows:

- Probabilistic expression of assessment results helps to numerically present the knowledge about measurement process, prediction and uncertainties related to the result. Additionally, results that are presented based on the simulation of the degradation process are a simplification of reality, which means that the assessed condition must decrease the uncertainty. Using the condition profile of $95 \%$ confidence level instead of the average condition profile in a situation where transition probabilities are low is justified as this helps to keep the structure on the safe side by triggering interventions based on the condition state limit.

- Inspections help to reduce the uncertainty and generally postpone the time for intervention. Adding a limit to the uncertainty of the condition can cause a situation where intervention is triggered due to the uncertainty limit.

- Non-destructive testing methods are more accurate than visual inspections and are useful in extending the time interval between inspections due to a higher reduction rate of uncertainties.

- In addition to a reduction of uncertainty, improved assessment can have a different intervention outcome and the differences in the average condition state of visual assessment and common non-destructive tests can vary from $-20 \%(-0.8)$ to $+40 \%(+1.6)$.

- Compared to the 4-year inspection interval, optimal inspection scheduling keeps the level of uncertainty under the desired threshold value. Additional assessment based on cover and carbonation depth measurements is justified because the area of uncertainty is maximised and after 55 years, the time between inspections can only be extended with a better assessment.

Considering all the factors, it can be concluded that with simple improvements in assessment methodology it is possible to reduce the level of uncertainty in decision-making regarding the intervention activities of existing structures.

\section{ACKNOWLEDGEMENTS}

The authors acknowledge the support of Eurostruct endorsed by the EU Framework Program Horizon 2020, the Archimedes Foundation and Professor Karl Õiger Scholarship Foundation. The publication costs of this article were covered by the Estonian Academy of Sciences.

\section{REFERENCES}

AASHTO. 1993. Guidelines for Bridge Management Systems. American Association of State Highway and Transportation Officials. https://standards.globalspec.com/std/164939/aashto-gbms

AASHTO. 2011. The Manual for Bridge Evaluation. American Association of State Highway and Transportation Officials, Subcommittee on Bridges and Structures. file:///C:/Users/kirjastus/Downloads/previews_AASHTO_MBE-2_2011_pre.pdf

Andrade, C. and Alonso, C. 2004. Test methods for on-site corrosion rate measurement of steel reinforcement in concrete by means of the polarization resistance method. Mater. Struct., 37(9), 623-643. https://doi.org/10.1007/BF02483292

Bich, W., Cox, M. G. and Harris, P. M. 2006. Evolution of the 'Guide to the Expression of Uncertainty in Measurement'. Metrologia, 43(4), S161-S166. https://doi.org/10.1088/0026-1394/43/4/S01

Corotis, R. B., Ellis, H. J. and Jiang, M. 2005. Modeling of risk-based inspection, maintenance and life-cycle cost with partially observable Markov decision processes. Struct. Infrastruct. Eng., 1(1), 75-84. https://doi.org/10.1080/15732470412331289305

COST Action TU1402. 2015. Memorandum of Understanding Action TU1402. Quantifying the Value of Structural Health. European Cooperation in Science \& Technology (COST). https://www.cost.eu/actions/TU1402 (accessed 2021-01-21).

COST Action TU1406. 2015. Memorandum of Understanding Action TU1406. Quality Specifications for Roadway Bridges Standardization at a European Technology Level (BridgeSpec). European Cooperation in Sciecne \& Technology (COST). https://www.cost.eu/actions/TU1406/\#tabs|Name:overview (accessed 2021-01-21). 
Denysiuk, R., Moreira, A. V., Matos, J. C., Oliveira, R. M. and Santos, A. 2017. Two-stage multiobjective optimization of maintenance scheduling for pavements. J. Infrastruct. Syst., 23(3), 04017001. https://doi.org/10.1061/(ASCE)IS.1943-555X.0000355

Ferreira, C., Neves, L. C., Matos, J. C. and Soares, J. M. S. 2014. A degradation and maintenance model: Application to portuguese context. Proceedings of Bridge Maintenance, Safety, Management and Life Extension, 483-489. https://doi.org/10.1201/b17063-307

Ghodoosi, F., Abu-Samra, S., Zeynalian, M. and Zayed, T. 2018. Maintenance cost optimization for bridge structures using system reliability analysis and genetic algorithms. J. Constr. Eng. Manage., 144(2), 04017116. https://doi.org/10.1061/(ASCE)CO.1943-7862.0001435

Hajdin, R., Kušar, M., Mašović, S., Linneberg, P., Amado, J. and Tanasić, N. 2018. WG3 Technical Report. Establishment of a Quality Control Plan. https://www.tu1406.eu/wp-content/uploads/2018/09/tu1406_wg3_digital_vf.pdf

Hässelbarth, W., Golze, M., Noack, S. and Subaric-Leitis, A. 2006. Guide to the Evaluation of Measurement Uncertainty for Quantitative Test Results. https:/opus4.kobv.de/opus4-bam/frontdoor/index/index/docId/13871 (accessed 2021-01-22).

Hofer, E. 2018. The Uncertainty Analysis of Model Results: A Practical Guide. Springer, Cham. https://doi.org/10.1007/978-3-319$76297-5$

Ilbeigi, M. and Pawar, B. 2020. A probabilistic model for optimal bridge inspection interval. Infrastructures, 5(6), 47. https://doi.org/10.3390/infrastructures5060047

Jackson, C. H. 2011. Multi-state models for panel data: the msm package for R. J. Stat. Softw., 38(8), 1-28.

JCGM 2008. JCGM 100:2008(E). https://www.iso.org/sites/JCGM/GUM/JCGM100/C045315e-html/C045315e.html?csnumber=50461 (accessed 2021-01-13).

Kallen, M. J. and van Noortwijk, J. M. 2006. Statistical inference for Markov deterioration models of bridge conditions in the Netherlands. In Proceedings of the Third International Conference on Bridge Maintenance, Safety and Management (IABMAS), Porto, Portugal, July 16-19, 2006 (Cruz, P. J. S., Frangopol, D. M. and Neves, L. C., eds), pp. 16-19, Taylor \& Francis, London.

Kang, M. and Adams, T. 2010. Sensitivity analysis of bridge health nidex by various element failure costs and element conditions. In TRB 89th Annual Meeting Compendium of Papers DVD, Washington, D.C., USA, January 10-14, 2010, 10-2544.

Kušar, M. 2014. Development of bridge management system for roads and highways. Doctoral dissertation. University of Ljubljana, 2014 (in Slovenian).

Kušar, M. and Šelih, J. 2014. Analysis of bridge condition on state network in Slovenia. Građevinar, 66(9), 811-822.

Kušar, M., Galvão, N. and Sein, S. 2019. Regular bridge inspection data improvement using non-destructive testing. In Proceedings of Life Cycle Analysis and Assessment in Civil Engineering: Towards an Integrated Vision, Ghent, Belgium, 2018 (Caspule, Taerwe and Frangopol, eds), pp.1793-1797, Taylor \& Francis, London.

Minister of Economic Affairs and Infrastructure. 2018. Requirements for Road Conditions. State Gazette (in Estonian). https://www.riigiteataja.ee/akt/102112018003?leiaKehtiv (accessed 2021-01-27).

Mirzaei, Z., Adey, B. T., Klatter, L. and Kong, J. S. 2014. The IABMAS Bridge Management Committee Overview of Existing Bridge Management Systems. International Association for Bridge Maintenance and Safety (IABMAS).

Neves, L. C. and Frangopol, D. M. 2005. Condition, safety and cost profiles for deteriorating structures with emphasis on bridges. Reliab. Eng. Syst. Saf., 89(2), 185-198. https://doi.org/10.1016/j.ress.2004.08.018

Neves, L. C. and Frangopol, D. M. 2008. Life-cycle performance of structures: combining expert judgment and results of inspection. In Life-Cycle Civil Engineering (Neves, L. C. and Frangopol. D. M., eds), pp. 429-434, CRC Press, London. https://doi.org/10.1201/9780203885307-66

Neves, L. A., Frangopol, D. M. and Cruz, P. J. 2006. Probabilistic lifetime-oriented multiobjective optimization of bridge maintenance: Single maintenance type. J. Struct. Eng., 132(6), 991-1005. https://doi.org/10.1061/(ASCE)0733-9445(2006)132:6(991)

Neves, L. A., Frangopol, D. M. and Petcherdchoo, A. 2006. Probabilistic lifetime-oriented multiobjective optimization of bridge maintenance: Combination of maintenance types. J. Struct. Eng., 132(11), 1821-1834. https://doi.org/10.1061/(ASCE)07339445(2006)132:11(1821)

Phares, B. M., Washer, G. A., Rolander, D. D., Graybeal, B. A. and Moore, M. 2004. Routine highway bridge inspection condition documentation accuracy and reliability. J. Bridge Eng., 9(4), 403-413. https://doi.org/10.1061/(ASCE)1084-0702(2004)9:4(403)

Regan, H. M., Colyvan, M. and Burgman, M. A. 2002. A taxonomy and treatment of uncertainty for ecology and conservation biology. Ecol. Appl., 12(2), 618-628. https://doi.org/10.1890/1051-0761(2002)012[0618:ATATOU]2.0.CO;2

Roberts, J. E. and Shepard, R. 2000. Bridge management for the 21st century. Transp. Res. Rec., 1696(1), $197-203$. https://doi.org/10.3141/1696-63

Rouhan, A. and Schoefs, F. 2003. Probabilistic modeling of inspection results for offshore structures. Struct. Saf., 25(4), 379-399. https://doi.org/10.1016/S0167-4730(03)00016-X

Rücker, W., Hille, F. and Rohrmann, R. 2006. Guideline for the Assessment of Existing Structures. SAMCO Final Report.

Sein, S., Matos, J. C. and Idnurm, J. 2017. Statistical analysis of reinforced concrete bridges in Estonia. Baltic J. Road Bridge Eng., 12(4), 225-233. https://doi.org/10.3846/bjrbe.2017.28

Sein, S., Idnurm, J. and Matos, J. C. 2019. Uncertainty in condition prediction of bridges based on assessment method - Case study in Estonia. International Association for Bridge and Structural Engineering (IABSE). http://repositorium.sdum.uminho.pt/ (accessed 2021-01-13).

Sheils, E., O'Connor, A., Schoefs, F. and Breysse, D. 2012. Investigation of the effect of the quality of inspection techniques on the optimal inspection interval for structures. Struct. Infrastruct. Eng., 8(6), 557-568. https://doi.org/10.1080/15732479.2010.505377

Straub, D. and Faber, M. H. 2003. Modeling dependency in inspection performance. In Proceedings of the 9th International Conference on Application of Statistics and Probability in Civil Engineering, San Francisco, CA, USA, July 6-9, 2003 (Der Kiureghian, A., Madanat, S. and Pestana, J. M., eds), pp. 1123-1130, Millpress, Rotterdam. 
Taffe, A. 2018. Condition assessment: From good choice of methods to reliable results that meet the customer demand. MATEC Web of Conferences, 199, 01008. https://doi.org/10.1051/matecconf/201819901008

Taffe, A. and Gehlen, C. 2009. Methodology for the validation of NDT-CE methods using transit time measurement. In Proceedings of the 7th International Symposium on Non Destructive Testing in Civil Engineering, Nantes, France, June 30-July 3, 2009 (Derobert, X. and Abraham, O., eds), pp. 997-1002, NDTCE.

Thompson, P. D. and Shepard, R. W. 2000. AASHTO. Commonly-recognized bridge elements. In Materials for National Workshop on Commonly Recognized Measures for Maintenance, Scottsdale, AZ.

USSR Mintransstroy. 1962. Standard project. Issue 56-addition. Selection of structures of reinforced concrete precast spans without diaphragms with periodic profile frame reinforcement. Spans: $7.5 \mathrm{~m} ; 10.0 \mathrm{~m} ; 12.5 \mathrm{~m} ; 15.0 \mathrm{~m}$. Loads: N-13 and NG-60; N-18 and NK-80. Dimensions: G-6; G-7 and G-8 with pavement widths of 0.75 and $1.5 \mathrm{~m}$ (in Russian). https://meganorm.ru/Index2/1/4293831/4293831715.htm (accessed 2021-01-28).

USSR Mintransstroy. 1963. Standard project. Issue 167. Reinforced concrete prefabricated spans without diaphragms with periodic profile frame reinforcement made of 35GS steel. Spans: 7.5; 10.0; 12.5 and 15.0 m. Load: N-30 and NK-80. Dimensions: G-7, G-8, G-9 and G-10,5 with pavement width of 1.0 and $1.5 \mathrm{~m}$ (in Russian). https://meganorm.ru/Index2/1/4293777/4293777392.htm (accessed 2021-02-28).

Zambon, I., Vidovic, A., Strauss, A. and Matos, J. 2018. Prediction of the remaining service life of existing concrete bridges in infrastructural networks based on carbonation and chloride ingress. Smart Struct. Syst., 21(3), 305-320. https://doi.org/10.12989/sss.2018.21.3.305

Zambon, I., Vidovic, A., Strauss, A. and Matos, J. 2019. Condition prediction of existing concrete bridges as a combination of visual inspection and analytical models of deterioration. Appl. Sci., 9(1), 148. https://doi.org/10.3390/app9010148

Zhang, C., Zayed, T. and Hammad, A. 2008. Resource management of bridge deck rehabilitation: Jacques Cartier bridge case study. J. Constr. Eng. Manage., 134(5), 311-319. https://doi.org/10.1061/(ASCE)0733-9364(2008)134:5(311)

\section{Sildade haldamise optimeerimine lähtuvalt seisukorra hindamisega kaasnevast määramatusest}

\section{Sander Sein, Jose Campos Matos, Juhan Idnurm, Martti Kiisa ja Mário Coelho}

Sildade haldamine on viimase paarikümne aastaga märkimisväärselt muutunud, sest oma otsuste tegemisel arvestavad omanikud lisaks seisukorra infole ka alternatiivsete parendustegevustega. Vaatamata muutunud olukorrale vajavad õiged otsused piisavalt täpset sisendit, mis jätkuvalt põhinevad registri- ja seisukorrainfol. Antud töös on keskendutud seisukorra hindamisele, tutvustades võimalusi selle edasiarendamiseks täpsemate mittepurustavate katsemetoodikatega ja analüüsides eri võimalusi, muutmaks hindamistevaheline aeg optimaalsemaks, tagades samal ajal, et otsuse aluseks oleva prognoosimudeli määramatus jääb alla piirväärtuse. Täpsemate mittepurustavate katsemetoodikate hõlpsamaks kasutuselevõtuks on autorid välja pakkunud üleminekumaatriksi, mis on koostatud lähtuvalt Transpordiameti praegusest kvalitatiivsel visuaalsel ülevaatusel põhinevast hindamissüsteemist. Töös on analüüsitud kolme erinevat seisukorra hindamisega kaasneva määramatuse aspekti, mis kõik põhinevad reaalsetel andmetel ja mis näitavad, kui oluline on arvestada sildade haldamisel määramatusega. Näited on koostatud Eesti riigiteedel enam levinud sildadelt kogutud andmete alusel, mida Markovi ahelate Monte Carlo algoritmide simulatsiooni tulemusena väljendatakse tõenäosuslike seisukorra väärtustena ja mille uuendamisel kasutatakse Bayesi meetodit. Tulemused kinnitavad, et seisukorra prognoosimise ja hindamisega kaasnevad kõrvalekalded mõjutavad elemendi seisunditaseme määramatust. Viimane omakorda mõjutab planeeritud ülevaatuse ja parendustegevuse aega ja seeläbi üldisi kulusid ning otsuste usaldusväärsust. 